\title{
Comparison of continuous versus intermittent furosemide administration in dogs with acute heart failure
}

\author{
Zita Filipejová, Carlos Fernando Agudelo Ramírez, Michal Crha \\ University of Veterinary and Pharmaceutical Sciences Brno, Faculty of Veterinary Medicine, \\ Small Animal Clinic, Brno, Czech Republic
}

Received April 11, 2016

Accepted June 23, 2016

\begin{abstract}
Pulmonary oedema is a life-threatening condition which should be treated promptly in the emergency room with oxygen, cage rest, and diuretic therapy. Traditionally, bolus administration of furosemide is the treatment of choice. However, there is emerging information that continuous rate infusion might be more effective than bolus injections in relieving clinical signs and producing a lower rate of complications such as azotaemia, dehydration, and electrolyte imbalances. We tested the effect of furosemide both in bolus (4-6 mg/kg intravenously) and continuous rate infusion $(1 \mathrm{mg} / \mathrm{kg} / \mathrm{h})$ in 30 dogs that had been presented with fulminant pulmonary oedema during 2 days of hospitalization. No differences in the selected biochemical indicators between the groups were found. There were significant differences in blood urea nitrogen in the bolus injection group and creatinine and phosphorus in the continuous rate infusion group between days 1 and 2 . The results of this study showed no differences in the approach of furosemide administration in the management of pulmonary oedema. Both methods may cause renal and electrolyte complications, however, further studies with a larger number of patients are recommended.
\end{abstract}

Diuretics, canine, continuous rate infusion, pulmonary oedema

Pulmonary oedema (PO) is generally accepted as an abnormal accumulation of fluid in the extra-vascular space of the lung that usually threatens the life of the patient (Kittles on 1998). This condition may develop when the hydrostatic and oncotic forces in the lungs (the Starling forces) indicate an increase in driving pressure for fluid filtration or a weakening of the barriers that normally restrain fluid and protein movement. The balance of Starling forces in the lungs is generally stated as favouring reabsorption because of the clinical fact that the lungs should be generally clear to ensure efficient gas exchange. Under normal conditions, there is a small net outward movement of fluid, but if any one of the Starling forces changes in the direction that favours increased fluid filtration, PO may develop (Bachmann and Waldrop 2012). The last is very commonly caused by an increase in pulmonary capillary hydrostatic pressure secondary to left-sided heart disease (Glaus et al. 2010; Murray 2011; Bachmann and Waldrop 2012). However, other conditions can lead to non-cardiogenic pulmonary oedema (NPO) also by changes in the movement of Starling forces such as injuries to the alveolar-capillary barriers in the lung parenchyma, neurogenic disease or upper airway obstruction (Glaus et al. 2010). There is a third type of PO from lymphatic insufficiency, but this seems to have little clinical importance (Kittles on 1998).

There are several congenital and acquired heart diseases, which may be permanent or temporary, that cause congestive heart failure (CHF). The most common aetiologies of heart failure in dogs are the degenerative mitral valve disease (DMVD) (Atkins et al. 2009) and dilated cardiomyopathy (DCM) (Glaus et al. 2010). Less common causes include congenital heart disease, myocarditis or endocarditis, drug-induced heart failure (e.g., doxorubicin) (Chatterjee et al. 2010; Gava et al. 2013) or sustained cardiac

Address for correspondence:

MVDr. Zita Filipejová

Small Animal Clinic

Palackého tř. 1949/1, 61242 Brno

University of Veterinary and Pharmaceutical Sciences Brno 
dysrhythmias (Kittles on 1998). When the mitral valve becomes damaged or incompetent, a portion of the left ventricular stroke volume is ejected backward, increasing left atrial pressure. This additional volume enhances the pulmonary venous return that enters the ventricle during diastole causing volume overload of the left atrium and the left ventricle, which as a consequence leads to dilation and hypertrophy. These events will provoke pulmonary venous congestion that finally results in PO. In turn, pressure caused by pulmonary congestion can damage the right side of the heart because of the increased workload to ensure lung circulation (Kittles on 1998).

The initial goals of therapy in cardiogenic pulmonary oedema include increasing arterial partial pressure of oxygen $\left(\mathrm{PO}_{2}\right)$ and reducing oxygen demand (oxygen therapy and cage rest), instituting diuresis, and decreasing the ventricular load while supporting blood pressure, tissue perfusion and renal function (Glaus et al. 2010). Diuretics are considered the most effective medication for the symptomatic treatment of CHF in both human and veterinary medicine (Kittleson 1998; Adin et al. 2003; Harada et al. 2015). Loop diuretics inhibit the sodium-potassium-chloride cotransporter in the thick ascending limb of Henle's loop and are considered one of the most potent classes of diuretics. These drugs cause urinary loss of water, hydrogen ions, and electrolytes, including phosphorus $(\mathrm{P})$, potassium $\left(\mathrm{K}^{+}\right)$, sodium $\left(\mathrm{Na}^{+}\right)$, chloride $\left(\mathrm{Cl}^{-}\right)$, calcium $\left(\mathrm{Ca}^{++}\right)$and magnesium $\left(\mathrm{Mg}{ }^{2+}\right)$ (Johansson et al. 2003; Felker 2010). Among loop diuretics, furosemide is the most commonly prescribed in human and veterinary cardiology (Adin et al. 2003). The dose, route, and frequency of furosemide administration is variable, depending on the severity of CHF, but it is typically administered intravenously (i.v.) as an intermittent bolus every 4 to $6 \mathrm{~h}$ (Adin et al. 2003) for the initial treatment of PO in dogs. In certain fulminant cases, furosemide may be administered even at 30-60 min intervals. The diuretic effect of furosemide lasts only 1 to $2 \mathrm{~h}$ after each bolus, and rebound sodium and water retention because of neuro-humoral activation can occur between doses (Hinchcliff et al. 1991; Johansson et al. 2003). Continuous rate infusion (CRI) of furosemide in humans has been shown to result in more diuresis with less intravascular volume shifts than an equivalent 24-h cumulative dose of furosemide administered by bolus, presumably resulting in less neurohumoral activation (Adin et al. 2003). A high-dose bolus injection of furosemide also can result in toxic blood concentrations; with the specific concern of ototoxicity in humans (Adin et al. 2003; Felker et al. 2011). The administration of CRI furosemide overcomes this concern by delivering furosemide molecules continuously to the nephron with less variation in serum and renal tubular drug concentrations. A large human study showed that furosemide CRI is safe, effective and less nephrotoxic than intermittent boluses in patients admitted with acute decompensated heart failure and signals a shorter hospital stay and lower readmission rates at 30 days (Aziz et al. 2011). The CRI also has been tested in animals with promising results (Adin et al. 2003), however, the use of furosemide CRI in patients with naturally acquired heart disease has not been studied (Dormans et al. 1996). The aim of this study was to compare clinical and selected blood indices of i.v. bolus against CRI furosemide administration in dogs admitted to hospitalization with fulminant PO.

\section{Materials and Methods}

\section{Animals}

In total, 30 client-owned dogs were included in the study. All dogs were inpatients at the Department of Internal Medicine at the Small Animal Clinic at the University of Veterinary and Pharmaceutical Sciences Brno, Czech Republic. The mean age and weight of dogs were 11.2 years and $10.5 \mathrm{~kg}$, respectively; 17 were males and 13 were females. There were 8 Chihuahuas, 6 Yorkshire terriers, 5 mongrel dogs, 2 Dachshunds, 2 Miniature schnauzers, 2 Miniature French poodles, and one of each of the following breeds: Caucasian shepherd, Maltese, Doberman, Cocker Spaniel and Weimaraner. 


\section{Study design}

The study was designed to be a single-blinded randomized controlled clinical trial.

The main inclusion criterion was the presence of PO based on the history, clinical examination, and thoracic radiographs (where possible due to the clinical status). Cardiogenic PO was diagnosed in 29 dogs and noncardiogenic PO in one dog (upper airway obstruction). All of the included patients had previously received oxygen therapy in a cage or flow-by and oximetry was obtained. An intravenous catheter was inserted, and blood samples for haematology, biochemistry (total proteins, albumin, glucose, alkaline phosphatase (ALP), alanine aminotransferase (ALT), aspartate aminotransferase (AST), bilirubin, blood urea nitrogen [BUN], creatinine, $\mathrm{P}$, $\mathrm{K}^{+}, \mathrm{Na}^{+}, \mathrm{Cl}^{-}$and $\mathrm{Ca}^{++}$), N-terminal pro-brain natriuretic peptide (NT-proBNP) and troponin I were collected. All dogs received furosemide (Furosemide forte ${ }^{\circledR}$, BB Pharma, Czech Republic) and were randomly divided into 2 groups of 15 individuals: patients receiving bolus injections (Group A) and patients receiving CRI (Group B).

Group A received $6 \mathrm{mg} / \mathrm{kg}$ i.v. of furosemide once (always diluted in saline to avoid phlebitis). According to the clinical status, furosemide was re-administered at boluses of $4 \mathrm{mg} / \mathrm{kg}$ every $30 \mathrm{~min}$ in cases when respiration rate was about $90 / \mathrm{min}$. When the respiration rate decreased to $60 / \mathrm{min}$, furosemide was given every hour. Once the respiration rate decreased to $40 / \mathrm{min}$, the bolus was given every $2 \mathrm{~h}$. On day 2 of hospitalization, patients received furosemide $\times 4$ daily when the respiration rate was within the normal range, when auscultation of the lungs was without crackles, or when the patient showed no signs of orthopnoea. Group B was administered furosemide CRI at $1 \mathrm{mg} / \mathrm{kg} / \mathrm{h}$ and; after $48 \mathrm{~h}$ the dose was decreased to $0.5 \mathrm{mg} / \mathrm{kg} / \mathrm{h}$. Blood samples were collected every day for haematology and biochemistry.

Other medications administered to both groups consisted of pimobendan (Vetmedin ${ }^{\circledR}$, Boehringer Ingelheim, Germany) at a dose of $0.2 \mathrm{mg} / \mathrm{kg}$ p.o. twice daily and aminophylline (Syntophyllin ${ }^{\circledR}$, BB Pharma, Czech Republic) at a dose of $8 \mathrm{mg} / \mathrm{kg}$ i.v. $\times 3$ daily.

Statistical analysis

The results were expressed as means \pm SD. Normality of variables was tested using Shapiro-Wilk test. Differences between groups were evaluated using Mann-Whitney test, and during the study in each group using Wilcoxon test. All tests were two-tailed and carried out at the 0.05 level of significance.

\section{Results}

A comparison between bolus and CRI administration of furosemide over a period of 2-day hospitalization showed no significant differences $(P>0.05)$ in the evaluated values. Unfortunately, seven patients died during the first day of hospitalization, subsequently, all calculations were done on the 23 patients that survived at least until day 2. Additionally, significant differences were found inside the groups before and after furosemide administration: $\mathrm{K}^{+}$decreased significantly in group $\mathrm{A}(4.1 \pm 0.8$ on day $1 ; 3.2 \pm 0.4$ on day $2)$ and in group B ( $4.4 \pm 0.7$ on day $1 ; 3.2 \pm 0.6$ on day 2$)$ (Fig. 1). Blood urea nitrogen was higher in group A (15.8 \pm 9.1 on day $1 ; 22.6 \pm 11$ on day 2$)$ (Fig. 2). Creatinine and Pwere higher in group $\mathrm{B}$ (creatinine $73 \pm 12$ on day $1 ; 116 \pm 35$ on day 2 ; and $\mathrm{P} 1.8 \pm 0.7$ on day 1 ; $2.4 \pm 0.6$ on day 2 ). Other evaluated values did not show significant differences.

\section{Discussion}

Traditionally, repeated bolus injections of furosemide have been the mainstay in the treatment of fulminant PO in combination with cage rest and oxygen delivery (Glaus et al. 2010). However, furosemide at higher doses (4-6 mg/kg) may produce side effects such as fluid and electrolyte abnormalities (e.g. hypokalaemia), nephrotoxicity, ototoxicity, bone marrow suppression, vomiting, diarrhoea, or central nervous system disorders such as seizures or coma (Luciani et al. 1997; Johansson et al. 2003). Furthermore, CRI potentially reduces the so-called diuretic resistance like the rebound phenomenon and maintains more consistent diuresis (Adin et al. 2003). In addition, CRI has been associated with lower peak plasma concentrations of furosemide, which may be associated with a lower incidence of side effects (Michael Felker 2010; Oh and Han 2015).

We administered higher doses of furosemide in both groups of dogs following the recommendations of the American College of Internal Veterinary Medicine for patients presented in stage C1 or D1 with presence of PO (Atkins et al. 2009; Felker et al. 2011). 
BOLUS

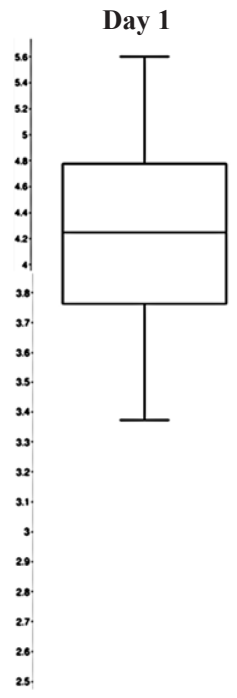

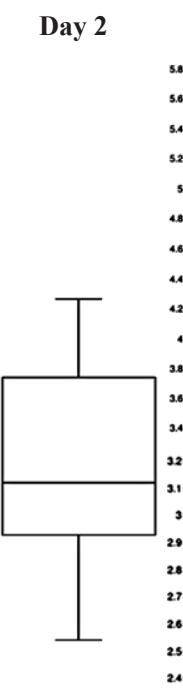

CRI

Day 1

Day 2

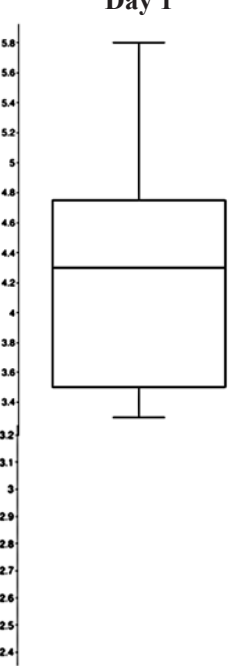

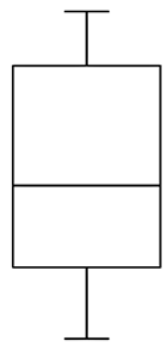

Fig. 1. Potassium concentration after bolus and continuous rate infusion (CRI) furosemide administration during 2 consecutive days. There is a parallel significant decrease of the medians of potassium (bolus injection: 4.25 to 3.1; CRI 4.3 to $3.1 \mathrm{mmol} / 1$ ) leading to hypokalaemia. Potassium column values are expressed in mmol/1.

Day 1

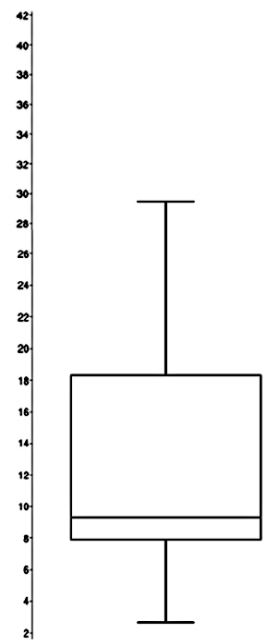

Day 2

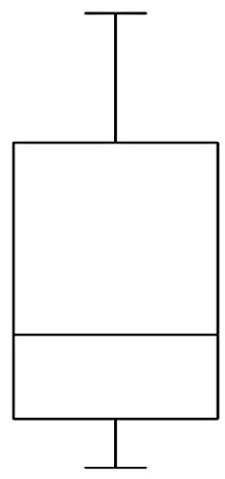

Fig. 2. Changes of blood urea nitrogen (BUN) values after bolus injection during 2 days. There is a striking increase on day 2 (from 9.35 to $19.6 \mathrm{mmol} / \mathrm{l}$ ). BUN column values are expressed in $\mathrm{mmol} / 1$.

Patients have a structural abnormality and current or previous clinical signs of heart failure caused by CVHD. Stage C includes all patients that have had an episode of clinical heart failure. Stage D includes patients with refractory heart failure. Our results demonstrated 
that there were no significant differences in the selected biochemical indicators when using CRI or bolus injection protocols. These results are similar to those previously described by Copeland et al. (1983) who evaluated the diuretic effect of furosemide administered by bolus injection and CRI in 18 cardiac surgery patients. Nine patients received $0.3 \mathrm{mg} / \mathrm{kg}$ of furosemide as a bolus injection at time 0 and again $6 \mathrm{~h}$ later or $0.5 \mathrm{mg} / \mathrm{kg} / \mathrm{h}$ of furosemide as a constant infusion for $12 \mathrm{~h}$. There were no significant differences between the groups with respect to age, weight, creatinine clearance, changes in $\mathrm{Na}^{+}$, and $\mathrm{K}^{+}$contents, total urinary concentrations of $\mathrm{Na}^{+}$and $\mathrm{K}^{+}$, or total urine volume for $12 \mathrm{~h}$ (Copeland et al. 1983). Another study carried out on humans by Allen et al. (2010) also found similar results, where no significant differences were shown between bolus at a dose of $162 \pm 48 \mathrm{mg} / 24 \mathrm{~h}$ twice a day and at a dose of CRI $162 \pm 52 \mathrm{mg}$ of furosemide. The results of serum creatinine, urine output, and length of stay of hospitalization were similar (Allen et al. 2010).

We expected a certain degree of dehydration in our patients, intended to stabilize their clinical situation; consequently, we expected different degrees of electrolytic and renal involvement. As a consequence of the higher doses and rapid volume depletion, several changes were found: hypokalaemia was detected to be significant in both groups; increased creatinine and phosphorus was observed in the CRI group and increased BUN was also detected in the bolus injection group. Our findings are consistent with those reported in a human study by Lahav et al. (1992) where people were hospitalized with class 3-4 chronic heart failure (CHF, New York Heart Association classification). The serum creatinine was increased after CRI furosemide more than bolus therapy. Serum creatinine concentration was noted in one during continuous infusion following loading dose (LDCI). One group received i.v. bolus injections of 30 to $40 \mathrm{mg}$ of furosemide as a loading dose followed immediately by a CRI of 2.5 to $3.3 \mathrm{mg} / \mathrm{h}(60$ to $80 \mathrm{mg} /$ day $)$ for $48 \mathrm{~h}$. The second group was treated with three i.v. bolus injections of 30 to $40 \mathrm{mg}$ every $8 \mathrm{~h}$ also for 2 days (Lahav et al. 1992). In spite of that, furosemide CRI produced significantly greater diuresis and natriuresis than bolus injections; there were no significant differences in sideeffects including hypovolaemia, electrolyte disturbances, hyperuricaemia and metabolic alkalosis between the two methods (Lahav et al. 1992). Ostermenn et al. (2007) also noted similar findings in another diuretic study using CRI furosemide and bolus therapy, where no differences in terms of mortality and changes in renal function were found (Ostermann et al. 2007).

Creatinine elevation during CRI furosemide and bolus therapy as noted in our patients may be of great concern for renal impairment. Creatinine concentration is currently considered the best indirect marker of glomerular filtration rate and is also used by the International Renal Interest Society (IRIS) to stage canine and feline chronic kidney disease. An abnormally high plasma creatinine value is assumed to indicate the loss of at least $65-75 \%$ of the renal mass (Lefebvre 2011). Unfortunately, due to a lack in ulterior follow-ups and urine evaluations during the study, we cannot support the evidence of tangible renal damage. The most common reason for renal impairment induced by i.v. furosemide is probably related to its hypotensive effect in patients with refractory CHF (Lefebvre 2011).

The CRI of furosemide in humans has been shown to result in more diuresis with less intravascular volume shifts than an equivalent 24-h cumulative dose of furosemide administered by bolus probably due to less renin-angiotensin-aldosterone system (RAAS) activation (Dormans et al. 1996; Adin et al. 2003). Dormans et al. (1996) concluded that in patients with severe heart failure, high doses of CRI furosemide (mean daily dosage of $690 \mathrm{mg}$ ) are more efficacious than bolus injection and cause less ototoxic effects (Dormans et al. 1996). Another report found that CRI furosemide had significantly better natriuretic and diuretic effects than bolus administration of the same dose of the drug in 
patients with advanced chronic renal insufficiency (CKD) (Sanjay et al. 2008). Studies in veterinary medicine are scarce and most of them performed under experimental conditions on healthy animals. The first reference of such comparison was achieved by Hori in 2009 in healthy anaesthetized dogs, which were aleatory divided into placebo and CRI groups (Hori et al. 2010). Furosemide was infused at $0.5 \mathrm{mg} / \mathrm{kg} / \mathrm{h}$ for $8 \mathrm{~h}$ in the CRI group or was injected at 0 and $4 \mathrm{~h}(2 \mathrm{mg} / \mathrm{kg})$ in the bolus group. The placebo received sterile saline. Urine output was significantly higher in the CRI group. Also $\mathrm{K}^{+}$and $\mathrm{Na}^{+}$excretion were significantly increased in both furosemide groups than in placebo dogs (Hori et al. 2010). Our results could be comparable to those of the Hori's study where the hypokalaemia found in both furosemide groups by assumption could be explained by significantly increased kaliuresis. However, some results of a recent veterinary study are contrary to our findings: CRI furosemide administered to healthy Greyhound dogs at moderate doses $(0.66 \mathrm{mg} / \mathrm{kg} / \mathrm{h})$ resulted in more diuresis, natriuresis, and calciuresis and less kaliuresis than when given by bolus at a dose of $3 \mathrm{mg} / \mathrm{kg}$ at 0 and $4 \mathrm{~h}$ (Adin et al. 2003). Nowadays, it is widely recognized that the Greyhound breed has unique biological and physiological features differing from those of other breeds of dogs (Vilar et al. 2008). In addition, healthy dogs very probably did not have chronic activation of the renin-angiotensin-aldosterone system as is in cardiac patients, thus excreting more water, $\mathrm{Na}^{+}$and retaining $\mathrm{K}^{+}$(Hori et al. 2010).

Finally, in normal horses, it was demonstrated that CRI furosemide at a dose of $0.12 \mathrm{mg} / \mathrm{k} / \mathrm{h}$ preceded by a loading dose of $0.12 \mathrm{mg} / \mathrm{kg}$ i.v. produced more diuresis during the first $8 \mathrm{~h}$ and more electrolyte urinary excretion $\left(\mathrm{P}, \mathrm{Cl}^{-}\right.$and $\left.\mathrm{Ca}^{++}\right)$when compared to bolus administration $(3 \mathrm{mg} / \mathrm{kg}$ ) (Johansson et al. 2003). The results of our study also show the opposite results based on the assumed decreased $\mathrm{P}$ excretion seen in CRI dogs (increased phosphataemia). This discrepancy might reflect species differences or could be due to chance.

This study certainly has important limitations such as the limited number of clinical cases, and the 8 dogs dying in result of a heart failure during the first $24 \mathrm{~h}$ of hospitalization. Also, an important fact is that we analysed data of clinical patients, in contrast to the above mentioned experimental studies on healthy animals. Therefore, there is the possibility of other organ diseases (e.g. chronic renal insufficiency) presented along with the heart failure that might have affected blood biochemical indicators.

Despite the fact that there were no significant differences in biochemical indicators of dogs treated by i.v. bolus and CRI furosemide administration, we suppose that CRI furosemide administration would be less damaging to renal function. Further studies on a larger group of clinical cases would be necessary to explain this question.

\section{Acknowledgements}

This study was supported by the institutional funds of the Faculty of Veterinary Medicine of the University of Veterinary and Pharmaceutical Sciences Brno.

\section{References}

Adin DB, Taylor AW, Hill RC, Scott KC, Martin FG 2003: Intermittent bolus injection versus continuous infusion of furosemide in normal adult greyhound dogs. J Vet Intern Med 17: 632-636

Allen LA, Turer AT, Dewald T, Stough WG, Cotter G, O’Connor CM 2010: Continuous versus bolus dosing of furosemide for patients hospitalized for heart failure. Am J Cardiol 105: 1794-1797

Atkins C, Bonagura J, Ettinger S, Fox P, Gordon S, Haggstrom J, Hamlin R, Keene B, Luis-Fuentes V, Stepien R 2009: Guidelines for the diagnosis and treatment of canine chronic valvular heart disease. J Vet Intern Med 23: 1142-1150

Aziz EF, Alviar CL, Herzog E, Cordova JP, Bastawrose JH, Pamidimukala CK, Tojino A, Park TS, Musat D, Kukin M 2011: Continuous infusion of furosemide combined with low-dose dopamine compared to intermittent boluses in acutely decompensated heart failure is less nephrotoxic and carries a lower readmission at thirty days. Hellenic J Cardiol 52: 227-235

Bachmann M, Waldrop JE 2012: Noncardiogenic pulmonary edema. Compend Contin Educ Vet 34: E1 
Copeland JG, Campbell DW, Plachetka JR, Salomon NW, Larson DF 1983: Diuresis with continuous infusion of furosemide after cardiac surgery. Am J Surg 146: 796-799

Dormans TP, Van Meyel JJ, Gerlag PG, Tan Y, Russel FG, Smits P 1996: Diuretic efficacy of high dose furosemide in severe heart failure: Bolus injection versus continuous infusion. J Am Coll Cardiol 28: 376-382

Felker GM, Lee KL, Bull DA, Redfield MM, Stevenson LW, Goldsmith SR, Lewinter MM, Deswal A, Rouleau JL, Ofili EO, Anstrom KJ, Hernandez AF, Mcnulty SE, Velazquez EJ, Kfoury AG, Chen HH, Givertz MM, Semigran MJ, Bart BA, Mascette AM, Braunwald E, O'connor CM 2011: Diuretic strategies in patients with acute decompensated heart failure. N Engl J Med 364: 797-805

Gava FN, Zacche E, Ortiz EM, Champion T, Bandarra MB, Vasconcelos RO, Barbosa JC, Camacho AA 2013: Doxorubicin induced dilated cardiomyopathy in a rabbit model: An update. Res Vet Sci 94: 115-121

Glaus TM, Schellenberg S, Lang J 2010: Cardiogenic and non cardiogenic pulmonary edema: Pathomechanisms and causes. Schweiz Arch Tierheilkd 152: 311-317

Harada K, Ukai Y, Kanakubo K, Yamano S, Lee J, Kurosawa TA, Uechi M 2015: Comparison of the diuretic effect of furosemide by different methods of administration in healthy dogs. J Vet Emerg Crit Care (San Antonio) 25: 364-371

Hinchcliff KW, Mckeever KH, Muir WW, 3rd 1991: Furosemide-induced changes in plasma and blood volume of horses. J Vet Pharmacol Ther 14: 411-417

Hori Y, Ohshima N, Kanai K, Hoshi F, Itoh N, Higuchi S 2010: Differences in the duration of diuretic effects and impact on the renin-angiotensin-aldosterone system of furosemide in healthy dogs. J Vet Med Sci 72: 13-18

Chatterjee K, Zhang J, Honbo N, Karliner JS 2010: Doxorubicin cardiomyopathy. Cardiology 115: 155-162

Johansson AM, Gardner SY, Levine JF, Papich MG, Lafevers DH, Fuquay LR, Reagan VH, Atkins CE 2003: Furosemide continuous rate infusion in the horse: Evaluation of enhanced efficacy and reduced side effects. $\mathrm{J}$ Vet Intern Med 17: 887-895

Kittleson MD 1998: Pathophysiology of heart failure. In: Kittleson MD (Ed.): Small Animal Cardiovascular Medicine. Mosby, St. Louis, pp 136-148

Lahav M, Regev A, Ra'anani P, Theodor E 1992: Intermittent administration of furosemide vs continuous infusion preceded by a loading dose for congestive heart failure. Chest 102: 725-731

Lefebvre HP 2011: Renal function testing. In: Joe Bartges DJP (Ed.): Nephrology and urology of small animals. Blackwell Publishing, Ames, pp. 91-96

Luciani GB, Nichani S, Chang AC, Wells WJ, Newth CJ, Starnes VA 1997: Continuous versus intermittent furosemide infusion in critically ill infants after open heart operations. Ann Thorac Surg 64: 1133-1139

Michael Felker G 2010: Diuretic management in heart failure. Congest Heart Fail 16 Suppl 1: S68-72

Murray JF 2011: Pulmonary edema: Pathophysiology and diagnosis. Int J Tuberc Lung Dis 15: 155-160

Oh SW, Han SY 2015: Loop diuretics in clinical practice. Electrolyte Blood Press 13: 17-21

Ostermann M, Alvarez G, Sharpe MD, Martin CM 2007: Frusemide administration in critically ill patients by continuous compared to bolus therapy. Nephron Clin Pract 107: 70-76

Sanjay S, Annigeri RA, Seshadri R, Rao BS, Prakash KC, Mani MK 2008: The comparison of the diuretic and natriuretic efficacy of continuous and bolus intravenous furosemide in patients with chronic kidney disease. Nephrology (Carlton) 13: 247-250

Vilar P, Couto CG, Westendorf N, Iazbik C, Charske J, Marin L 2008: Thromboelastographic tracings in retired racing greyhounds and in non-greyhound dogs. J Vet Intern Med 22: 374-379 